results of treatment of such problems as tabes dorsalis or aneurysm of the aorta.

Where a rural practitioner has to undertake the routine treatment of a case, under the observation and advice of a specialist, the former can have special training in the special technique and a very satisfactory partnership can be evolved. But apart from a scheme designed for remote rural areas, I think that it is generally a mistake to encourage general practitioners to diagnose and treat venereal diseases, as this very often leads to a lower standard of work.

\section{Future of Venereology}

I can forsee, if we now seize our opportunity, a new era in which venereal diseases will be treated exclusively by specialists. The latter will be men and women who have been selected rigorously for ability, scientific training, and personal attributes, and then trained comprehensively to have a broad foundation of medical and scientific knowledge with at least three years' special instruction in venereology. This ideal can be realized within quite a short time, perhaps within ten years, if permanent contracts are not made with those who have no real claim to specialist recognition. The standards of all specialists must be raised to the highest level by research, foreign travel, and periodic study leave. The benefits to this country and to sufferers throughout the world will be incalculable.

\section{The Venereologist of the Future}

The conception of the venereal disease specialist of the future is that he will be a physician of broad experience, with a scientific training, and with at least three years' exclusive training and experience in venereology. He must be a general physician with a special interest, in this case venereal disease, just as other physicians have a special interest in endocrinology, hæmatology, renal disease, or chest diseases.

He must be eligible to join the staff of hospitals as an associate physician, and might even aspire to the highest appointments in medicine.

If we look further ahead, I think the diagnosis and treatment of venereal disease could be merged into the general fields of diagnostic and curative medicine, and could take their place with special sessions for such maladies as the rheumatic disorders, diabetes, respiratory infections, etc. This would prevent too narrow specialism and avoid most of the social stigmata associated at present with venereal disease.

I hope that the Medical ,Society for the Study of Venereal Disease will formulate a standard of undergraduate training and will represent its views to the British Medical Association or other bodies. The standard of training and qualification of a specialist should also be defined. In addition the society might help by recommendations on the status and emoluments of the teacher of venereology.

\title{
DISCUSSION ON THE TEACHING OF VENEREAL DISEASE MANAGEMENT
}

Dr. Hamilton Wilkie (the President) said that the value of lantern slides could not be over-estimated. Patients brought before students, especially patients in a venereal disease department, were easily embarrassed, and slides arranged in a proper series avoided such embarrassment and served their purpose well.

Dr. Lees had also mentioned that it was possible in refresher courses given to general practitioners for lecturers to go too deeply into the subject. Dr. Hamilton Wilkie felt that his own experience in Leicester might be of interest in this connexion. In 1931 he gave a lecture on congenital syphilis to an audience of general practitioners. He was new to Leicester then, and was rather annoyed at the beginning of the lecture at seeing an unknown elderly practitioner yawning in the first row. He had been told afterwards that the lecture was far too advanced. A few years ago he had given Leicester medical men a lecture with lantern slides showing acute conditions and many blunders that might be made in venereal disease clinics, and they still talked about that lecture : it was a treat to see the results.
DR. R. R. Willcox said he had much enjoyed the lecture, especially the undergraduate part, but he was uncertain about the postgraduate part because if he understood Dr. Lees aright the budding specialist had to lead a subsidized existence for five years, and at the end of that time he was no longer wanted.

Colonel Harrison wished to join issue with Dr. Lees in his denunciation of the teaching of the dark-ground method to students. He thought it brought the method home to a student much more thoroughly when he had to set the microscope up, take the specimen, and demonstrate it for himself. Also the student should learn to stain films properly and to realize that there is a great difference between a bad Gram and a good Gram.

This brought him to a more fundamental point, which was that he would always teach venereal disease from the bottom upwards, in other words from the point of view of the pathologist. If a student really understood what was going on underneath, he was much more likely to draw correct inferences than if he were taught from the 
top, that such and such symptoms indicated so and so. If he were made to visualize what was taking place, what the spirochæte was doing or what the gonococcus was doing, he could deal with new situations on fundamental principles.

Colonel Harrison emphasized the value of visual teaching and of moving pictures, using films that could be stopped so that the lecturer could discuss points of interest. He knew of no better method of demonstrating technique to a big class. He used to show a film at St. Thomas's Hospital every Friday evening, one reel at each sitting, and with it he demonstrated technique in detail. It was attended by seventy volunteers every week, which testified to the fact that they were getting value. The film was followed by a clinical demonstration.

Clinical teaching was a tricky business, and the use of good models was valuable in supplementing this. He had many realistic models which he had brought from the St. Louis Hospital, Paris, some years ago. They had to be taken care of, but it was useful to be able to show the common rashes when a living specimen was not available.

Colonel Harrison also emphasized the value of a proper interpretation of laboratory reports, which would avoid many mistakes in diagnosis.

He endorsed what Dr. Lees had said about putting this work into the hands of properly trained specialists ; he would do away with the part-time half-trained general practitioner. The aim should be to have people treating venereal disease who were engaged entirely in this work.

DR. G. L. M. McElligotT admitted that his own system was rather at variance with that which Dr. Lees had advocated. He had always felt that when the student began his clinical training he was ignorant of anything about venereal or any other disease, but that from the moment he went into the casualty department he began seeing cases. On his first morning in casualty a case of perforating ulcer on the foot came to be dressed and he knew nothing about the reason for it. He (the speaker) had now instituted into his own medical school a course of preliminary lectures given by himself for students in the first three months of the clinical course. Half a dozen rather dogmatic lectures were given, and the students seemed to like them. It was important to trade on the fact that these students were learning pathology at the same time, and to try to teach the manifestations of syphilis and gonorrhœa with a strong pathological background.

It was a mistake to try to get in all the teaching about venereal disease during the last crowded six months before the final examination. There was no doubt about it that a good working knowledge of syphilis was a very good hook on which to hang medical knowledge, particularly if it were taught with a pathological bias : and the earlier it was attained the better.

That was his first suggestion. His second was that when the student was doing his medical course there should be a certain number of joint consultative demonstrations, as Dr. Lees had suggested, to which he could go. In other words, all, or nearly all the patients with aortic regurgitation drifted down to the venereal disease department, and if two or three cases of cardiovascular syphilis, neurosyphilis, and congenital syphilis could be got together once a month and brought to a keen physician he would be very glad of the material and to have a venereologist with him to tell him how the case was being dealt with.

Lastly, of course, the student must go to the clinic. Demonstrations of the key types of case were important but he thought it also important that the students should be able to sit down and listen to and watch the venereal patient being dealt with. He need not see too much ; if he went for a month on three evenings a week he would see quite enough. In his clinic they had six students allocated every month ; they rarely all came at the same time, and never more than two were allowed to attend the female clinic at the same time. He made it a rule that when students went to the venereal disease department they should always wear white coats, and when they went to the female side only one might accompany the doctor to the examination cubicle. As far as the patient was concerned the student was an assistant; female patients rarely objected. All one wanted to teach a student on the female side, apart from seeing lesionsand they were becoming few and far between, and could be demonstrated one at a time-was how to take specimens for pathological examination. They must learn how to take urethra! and cervical smears and to plant cultures. There were still far too many doctors who were content with vaginal smears.

Good coloured lantern slides or colour photographs projected by an epidiascope were invaluable for illustrating the various lesions of syphilis, and he made it a rule to show a representative collection of these during the final lecture of the course.

DR. RAY BETtLeY said he had asked a general practitioner how many fresh cases of venereal disease he had seen since he returned from the Army in 1945; the practitioner replied that he had not seen any. Asked how many cases of venereal disease of any kind he had seen, he replied that he had seen some cardiac patients on whom he had carried out the Wassermann test as a : routine, and he had found that two were positive. These were the only two cases he had treated during the last three years. He referred them to specialists and received recommendations for treatment, and he had since carried out the treatment on general lines. Dr. Bettley asked him what he would do if he saw a case of early venereal disease. He said he would send the pätient to hospital, to a clinic, or to a private specialist, that he would obtain advice as to treatment, and that he would carry on such treatment as he was recommended.

They must cut their coat according to their cloth. $\mathrm{He}$ was thinking of the undergraduate student. With what Dr. Lees had said regarding the postgraduate student and the training of the specialist (a very excellent discourse on a difficult subject) he could not agree more. He thought that Dr. Lees hinted in his last remarks that venereal diseases were becoming very largely the province: of the specialist. Dr. Lees mentioned the last-year student who was not capable of carrying out a good. Gram stain, but unless he became a pathologist or a venereologist the chances were that he would never want to do one. The students spent three and a half years cramming their heads with knowledge of every kind of disease, but what their teachers should try to do was to. turn out doctors who had a general grasp of what a patient was and how their clinical problems must be approached. They should be taught to become people. who could teach themselves as they moved round among. their patients. By trying to equip them with the knowledge of how to do a Gram stain, how to recognize the treponema, and so on, they were turned into half-baked specialists.

They were, in fact, being equipped to practise in places where round the corner they would have a venereologist, either in his consulting room or in the clinic at the hospital. He asked himself constantly- 
he had to teach venereal disease to undergraduateshow much to teach, where to leave off. To the general practitioner venereal disease was a social and epidemiological problem. How many general practitioners would ever use a dark-ground microscope? They must be practical about this.

The President said that he had very strong personal views on this question of the pathological training of venereologists. He disagreed a little with Dr. Lees because he had himself done three years full time in a laboratory and never regretted that training. He was trained in Glasgow by Professor J. Wyllie, whom he could remember saying, "It will take you three years before you can diagnose with certainty the gonococcus in a specimen taken from the female." He thought that was ridiculous, but as the years went on he thought there was a lot to be said for it. He was not talking about the training of the general practitioner, the medical student who was going into general work, but about the man who was going to specialize in venereal disease work.

DR. W. Neville Mascall thought that, if the student were going to be taught, he should be given a sound knowledge of these diseases ; if not, he should be taught to leave them alone entirely. Some practitioners who knew virtually nothing about these diseases were now treating them, as they thought that all they had to do was to give one or several injections of penicillin and the patient was cured. This line of action might be all right in a large percentage of cases, but in some it was definitely dangerous by leading the patient into that position of false security when he believed himself cured whereas as a matter of fact he was not. He had recently seen a case of "gonorrhœa" in which only a clinical diagnosis was made, and on that ground alone the patient was told that he would require seven days' treatment with penicillin. He was admitted to a nursing home and the penicillin was duly given, at the end of which course his discharge persisted. Dr. Mascall thought this proved that the patient never suffered from gonorrhœa and that the penicillin course was a waste of time and money.

He felt that the teaching of venereal diseases had been handicapped in the past by lack of financial assistance, and he hoped that this state of affairs would be remedied. When he was at the Whitechapel Clinic a series of films was made which dealt with most of the techniques employed in the treatment of venereal disease, such as venepuncture, etc. They managed to film the Treponema pallidum for teaching purposes. He supervised a film on the diagnosis and treatment of female gonorrhœa. In order to get the money to make these films they had to depend on the sale of gonorrhœal bags to male patients because no grant for such a purpose was available. By this method quite a good collection of films was made. He did not know what had happened to most of them, but his own was in the Medical Film Library. It was probably a little out of date now but it showed that with a little trouble the whole of the techniques employed could be filmed. He thought that a library could be formed to circulate copies which would be of a great help to all those engaged in teaching.

He was undertaking postgraduate teaching at present at the Institute of Urology, and he found that the first question the majority of the postgraduates asked was what were the prospects for the future at the end of the course. This was a difficult question to answer.

Dr. T. E. Osmond said that if all those who dealt with these diseases, whether general practitioners or specialists, would realize that there was a sociological side. that there was another infected person, it would go a long way towards eradicating venereal disease. He would also emphasize the necessity of teaching how to take specimens. The value of a pathologist's report was proportional to the excellence of the specimens he received. He himself got many bad specimens, and wondered if they were worth looking at at all. Colonel Harrison used to say, and he had always agreed with him and backed up his opinion, that every specialist in venereal disease should serve an apprenticeship in the pathological laboratory, Colonel Harrison did so, and so did the speaker. Nobody should be a specialist until he understood the various tests carried out in the laboratory, the method of carrying them out, and the manner of their interpretation: 65 per cent. of registered medical practitioners believed that a positive Wassermann reaction always meant syphilis, but that was not true.

DR. BATCHelor said it was important to teach undergraduates how to take smears even if they did not examine them but sent them to a laboratory. The staining could be left until afterwards. He was im: pressed by what Dr. McElligott said about students coming into contact with actual cases soon after they had left the more theoretical side. In their work as doctors they would deal with men and women, boys and girls and babies, not with lantern slides. He felt that lantern slides were useful to summarize the various manifestations of disease and he used them, but students must be given the opportunity to observe the patients themselves.

He was glad Dr. Lees emphasized the value of the teaching of venereal disease as helping in the teaching of general medicine. With regard to the teaching of specialists he thought Dr. Lees had evolved an excellent long-term policy. But many of those who aspired to be specialists had spent years in the services: they had got married and had children, and had to live. If they were provided for by the new health service so much the better; they could then spend the necessary number of years going through an excellent and extended course of training, including travelling, but at present many wanted to know how they were to get on.

The ideal that venereal diseases should be treated exclusively by specialists was excellent but was not attainable. For instance, in rural areas there were practitioners who treated the venereal diseases and who did the routine treatment reasonably well. They sent their patients to the clinic periodically to be examined and for directions for a new course of treatment. Hé did not think there would be any substitute for thesé men. In Scotland the idea of a motor car equipped as a travelling venereal disease centre was not favourably regarded; it was said that the local people would not go near the van if it were known what it was for.

DR. ForGan said there was talk that some day the National Health Service would include the Colonial Medical Service : but before that time came it might be necessary, if the incidence of venereal disease in this country continued to decline, for intending venereologists to obtain their clinical experience overseas. He suggested that the Ministry of Health, the Colonial Office, and the B.M.A. Venereal Disease Group should consider the possibility of arranging tours of duty in the West Indies or in West or East Africa, where their services were urgently needed and where they could obtain excellent clinical experience 
DR. CuRTis was surprised at Dr. Lees' restraint in his comments on the B.M.A. Committee's report on the Training of a Doctor. There were one or two points in their recommendations which were completely at variance with what Dr. Lees recommended. He would draw attention to them because it was important that these points should be discussed, and it was even more important that this Society should express its opinion on the Cohen Committee's recommendations regarding venereal disease.

In paragraph 391 it is stated that social measures designed to prevent and control venereal disease are properly taught in the social medicine course and not in the special venereal diseases course. How were the people responsible for teaching social medicine to obtain the first-hand knowledge of the social problems connected with venereal disease except in venereal disease clinics, or alternatively by talking to the venereologists working in those clinics? If the teaching of the sociological aspects of venereal disease was to be removed from the undergraduate's venereology course and put into the social medicine course, it would mean that the students would be likely to get second-hand teaching on that aspect of the subject instead of first-hand teaching.

Again the report states that, in the interests of teaching, cases requiring long courses of treatment should be in the responsible charge of the general physician although it might be administratively convenient for the patient to attend the venereal diseases department for his treatment. He did not understand why this was necessary for teaching purposes. The effect of this would be that the general physician would send his patient to the clinic to have his injection and that would be the sole function of the venereologist. Dr: Lees' suggestion of combined teaching by the cardiologist and the venereologist, and the venereologist and the general physician, was much the better recommendation.

On these points the Society should not allow the recommendations of the B.M.A. Committee on the training of a doctor to go uncriticized.

DR. D. NABarRo felt that Dr. Lees had taken a longterm view and that there were certain things which should be done more immediately. He agreed with Colonel Harrison that the proper way to study disease was from the pathological point of view, because it led the student to appreciate what was taking place in the patient's body.

He agreed with Dr. McElligott that to introduce the newly-fledged clinical clerk or dresser to venereal disease was useful, because there were all sorts of conditions in the casualty department which were directly or remotely associated with venereal disease. He remembered when he was a clerk in 1895 the house physician had diagnosed a child with blue legs as having Raynaud's disease and he had thought how clever that house physician was; but as a matter of fact it was a case of congenital syphilis.

It was possible to prevent congenital syphilis almost entirely, yet how often was the treatment carried out? How many of the thousands of expectant mothers there were annually in this country were given the Wassermann test?. Nobody knew. What did the midwives think about it? Many women were delivered by midwives. The Ministry of Health should insist that every woman should have a blood test as part of the ante-natal management. This would reduce the incidence of congenital syphilis very considerably. In 1943 there were 153 deaths from congenital syphilis, and probably there were many more which were not recognized.
He was not sure that penicillin would be effective in every case, but it had been very successful. It was not fair to the children that they should be born syphilitic or born dead ; in addition there were those who got interstitial keratitis, or were mental defectives and so forth. Recently at The Hospital for Sick Children, Great Ormond Street, a child had died and it was not known until necropsy was carried out that it had congenital syphilis. The mother had been to hospital but she had not been treated: The pregnant women in the country, and certainly many of the children, were not getting a square deal.

Dr. Nabarro asked who would pay the young man while he was undertaking the five years' training advocated by Dr. Lees?

The President thought the pooling of ideas and examples of teaching was most important. In this country some of the large centres not attached to universities had an enormous amount of material which could be used in the teaching.

DR. LEES, in reply, said he had not emphasized pathology as the basis of teaching, partly as the student had already been taught a great deal of pathology, and also because the tendency of the teachers of morbid anatomy was to demonstrate end results and gross examples of disease. It was impossible to teach convincingly the pathology of latent syphilis or the earliest phases of syphilis of the heart or central nervous system. But these phases of the disease could be taught clinically, and it was important that the student should think in terms of early aortitis rather than in terms of aneurysm or gross aortic incompetence.

Dr. McElligott's system had many merits, but he considered that six demonstrations of venereal disease in the early clinical period was probably excessive, as in this period it was usually thought more proper to be teaching the methods of examination of the patient. Syphilis was an excellent example of a chronic infective process with protean manifestations, and it was easy to co-ordinate physical examination, laboratory tests, psychological problems, and social factors.

He could not feel convinced that it was desirable in the venereology course to teach the technique of darkground microscopy or Gram staining to students, but it was necessary to teach the correct technique of collecting specimens, and of the utmost importance to teach the interpretation of laboratory reports, especially the reports of serological tests for syphilis. The technique of performance of tests was more properly a part of postgraduate training.

He also agreed that teaching must emphasize the limitations and abuses of penicillin in the treatment of venereal disease. There was undoubtedly a considerable amount of " tinkering" with venereal disease by practitioners who did not appreciate the possible harm to the individual and to the public.

The B.M.A. report on undergraduate education was really the starting point of this discussion, and he hoped that the Society's views would be expressed and considered by the B.M.A. In particular he agreed with Dr. Curtis that the venereologist whose daily task was to deal with the social problems of venereal disease should undertake this part of teaching in the preventive medicine or public health course. Otherwise, the students tended to receive " second-hand" information, from a person with little personal experience of the problems.

The suggestion in the B.M.A. report that long-term cases of syphilis, such as cardiac or neurological cases, 
should remain in the care of the physician was greatly deplored and should be opposed. It was becoming the rule to pass to the venereologist all cases of syphilis, and if the venereologist was a competent physician he would undoubtedly be recognized as the proper person to teach the undergraduate all matters relating to syphilis. This did not detract from the combined teaching on cases, or groups of cases, by two or more specialists having different interests. The venereologist, however, must be a well-trained physician, not an "injectioneer," otherwise he would deserve a lowly status.

There was obviously great opportunities of sharing and pooling material suitable for teaching, and he was interested to learn that there were so many films on venereal disease in existence. He hoped this discussion would encourage the sharing and exchange of photographic illustrations.

In the field of postgraduate education there was a great opportunity at present, for the National Health Service gave the opportunity to men and women of suitable type to obtain posts as registrars throughout the whole period of training. This system of training registrars would permit the replacement at an early date of all general practitioners, and others holding venereology appointments who did not have a full specialist training in venereology. This was an integral part of the scheme for venereal disease in the region with which he was associated. He considered that these young specialists would be adequately paid while in training and that there would be a great demand for properly trained specialists during the next ten years.

It was a very helpful and constructive suggestion that the young trainee or specialist should gain part of his experience in tropical countries, for there he would form a wider conception of the diseases and would have an immense volume of clinical work which was often of a type only rarely encountered in this country.

$\mathrm{He}$ insisted that specialist training in venereology must not be abbreviated or short term plans adopted, as these always implied a lowered standard. The standard to be achieved was that acceptable in other clinical specialities.

A year in a bacteriological laboratory-even a much longer time-would be an excellent part of the basic training of a specialist, not only for the practical knowledge of tests, but also for the scientific training he would receive.

The rural practitioner co-operating with the venereal disease specialist was recognized by the Ministry of Health, and it was proposed in Circular 2226 to continue the existing arrangements, but it would probably be an advantage to raise the standard of skill and experience demanded. The individual practitioners could rapidly gain proficiency in the technical procedures required by spending a few hours in the clinic with which they were co-operating.

He thought that Dr. Nabarro would find, if he surveyed the country, that it was rapidly becoming the rule to take blood tests for syphilis from all pregnant women : but even this procedure would not prevent all congenital syphilis and there were great difficulties in making such tests compulsory.

He hoped there would be continual growth in interest in the teaching of venereology both to students and graduates, and that a greater uniformity of practice and of requirements would be arranged in medical schools. At present there were great opportunities to raise the speciality to a standard that would command the respect of the profession and the confidence of the public. 